\title{
Overexpression of AGR2 Is Associated With Drug Resistance in Mutant Non-small Cell Lung Cancers
}

\author{
THI-THU-TRANG LUU*, DUC-HIEP BACH*, DONGHWA KIM, \\ RUOCI HU, HYEN JOO PARK and SANG KOOK LEE
}

College of Pharmacy, Natural Products Research Institute, Seoul National University, Seoul, Republic of Korea

\begin{abstract}
Background/Aim: The resistance to epidermal growth factor receptor tyrosine kinase inhibitors (EGFR-TKIs), such as gefitinib or erlotinib, is considered a major challenge in the treatment of patients with non-small cell lung cancer (NSCLC). Herein, we identified the critical roles of anterior gradient 2 (AGR2) in gefitinib (Gef) resistance of mutant NSCLC cells. Materials and Methods: Using datasets from a pair of NSCLCsensitive and NSCLC-resistant cells, immunoblotting, immunofluorescence and immunohistochemistry, and cell viability assays were applied to identify the effects of AGR2. Results: AGR2 was found to be significantly over-expressed in Gef-resistant cells and was highly associated with drug resistance, proliferation, migration, and invasion of cancer cells. Moreover, AGR2 and ADAMTS6 formed a negative feedback loop in drug-resistant cells. Conclusion: Modulation of overexpression of AGR2 in mutant NSCLC cells may be an attractive therapeutic strategy for the treatment of EGFR-TKI-resistant NSCLC.
\end{abstract}

Non-small cell lung cancer (NSCLC) is one of the major causes of cancer-related death worldwide, and comprises $85 \%$ of all lung cancer cases (1). Acquired drug resistance in tumor cells is a major obstacle in the field of anti-cancer chemotherapies. Likewise, NSCLC patients who initially show a good response to epidermal growth factor receptor tyrosine kinase inhibitors (EGFR-TKIs), such as gefitinib (Gef), acquire resistance to treatment (2). However, studies on the mechanisms through which overexpression of specific genes is involved in EGFR-

This article is freely accessible online.

*These Authors contributed equally to this study.

Correspondence to: Hyen Joo Park and Sang Kook Lee, College of Pharmacy, Natural Products Research Institute, Seoul National University, Seoul 151-742, South Korea. Tel: +82 28802475, Fax: +82 28889122, e-mail: phj00@snu.ac.kr (HJP), e-mail: sklee61@snu.ac.kr (SKL)

Key Words: AGR2, NSCLC, mutant NSCLC, gefitinib resistance, yuanhuadine, ADAMTS6.
TKI resistanse of NSCLC cells are scarce and its role remains to be elucidated. Therefore, novel approaches are required to elucidate their role in drug resistanse of cancer cells.

The anterior gradient-2 (AGR2) has been identified in Xenopus laevis and plays a critical role in cemet gland differentiation (3). Recent studies have suggested that elevated expression of AGR2 is correlated with cell proliferation, metastasis, and drug resistance in various human cancer cell lines, such as prostate (4), breast (5), and pancreatic cancer (6). Moreover, overexpression of AGR2 has been notably correlated with a poor outcome of estrogen receptor-negative breast cancer patients (7). AGR2 is also a pro-oncogenic protein that has been shown to stimulate the epidermal growth factor receptor (EGFR) ligand amphiregulin, regulate p53 signaling, and interact with the AAA+ protein Reptin (8), suggesting its modulatory roles in gene expression. High expression of AGR2 has also been shown to be predictive of poor survival in lung cancer (9). However, there is still a lack of insightful understanding of the role of AGR2 in EGFR-TKI-resistant NSCLC cells.

There are 19 members of zinc-dependent metalloproteases in the family of a disintegrin and metalloprotease with thrombospondin motifs (ADAMTS) (10). Recent reports suggest the critical roles of ADAMTSs in angiogenesis and cancer (11). They also play an important role in the modulation of extracellular matrix. For instance, ADAMTS1 metalloproteinase could stimulate tumorigenesis through the induction of a stromal reaction in vivo (12), while decreased expression of ADAMTS-1 may also accelerate invasion and migration in human breast tumors (13). Although several studies have reported the role of ADAMTSs in cancers, their precise functions in cancer cells are yet to be uncovered in detail, especially those of ADAMTS6. A previous study has indicated that ADAMTS6 was involved in the growth-inhibitory activity of breast cancer cells through modulation of the extracellular signalregulated kinase (ERK) pathway (14). ADAMTS6 is also dysregulated in some cancers, such as colorectal cancer (15), prolactin tumors (16), and breast cancer (17). However, the association of ADAMTS6 with NSCLC is still unclear, 
Table I. List of top 7 genes up-regulated in siAGR2-treated PC9-Gef cells compared to siCTL-treated PC9-Gef cells.

\begin{tabular}{lccc}
\hline No. & Gene symbol & Fold change & Gene description \\
\hline 1 & MARCH4 & 3.84 & Membrane associated finger 4 \\
2 & KRTAP2-3 & 3.27 & Keratin associated protein 2-3 \\
3 & $M I R 4731$ & 2.37 & MicroRNA 4731 \\
4 & MIR548C & 2.30 & MicroRNA 548c \\
5 & LOC400499 & 2.28 & Uncharacterized LOC400499 \\
6 & ADAMTS6 & 2.27 & ADAM metallopeptidase with thrombospondin type 1 motif 6 \\
7 & RNU5B-1 & 2.27 & RNA, U5B small nuclear 1 \\
\hline
\end{tabular}

especially its role in drug resistance of EGFR-mutant NSCLC cells. Herein, we demonstrate for the first time the relationship between AGR2 and ADAMTS6 in EGFR-TKIresistant mutant NSCLC cells by employing yuanhuadine (YD), a natural product anti-tumor agent.

\section{Materials and Methods}

Reagents and chemicals. RPMI 1640 medium and Opti_MEM Reduced Serum medium were purchased from Invitrogen (CA, USA). Rabbit anti-AGR2 was purchased from Cell Signaling (Danvers, MA, USA). Mouse anti-B-actin (C4) and anti-VEGF (A20) were purchased from Santa Cruz Biotechnology (Santa Cruz, CA, USA). Gefitinib (CAS No. HY-50895) was obtained from MedChemExpress (NJ, USA). Yuanhuadine (YD; purity > 98.5\%) was isolated and identified from a $\mathrm{CHCl}_{3}$-soluble fraction of the flowers of Daphne genkwa, as described previously (18). All chemicals were dissolved in DMSO.

Cell lines. PC9 and PC9-Gef cells were a gift from Dr. Jae Cheol Lee and Dr. Jin Kyung Rho (Asan Medical Center, Seoul, Korea). The cells were cultured in RPMI 1460 medium that was supplemented with $10 \%$ heat-inactivated fetal bovine serum (FBS) and antibiotics-antimycotics (PSF; $100 \mathrm{U} / \mathrm{ml}$ penicillin G sodium, $100 \mu \mathrm{g} / \mathrm{ml}$ streptomycin, and $250 \mathrm{ng} / \mathrm{ml}$ amphotericin B). PC9-Gef cells were grown in the presence of $1 \mu \mathrm{M}$ gefitinib. Cells were incubated at $37^{\circ} \mathrm{C}$ with $5 \% \mathrm{CO}_{2}$.

Western blot analysis. Immunoblotting analysis was performed according to our previously published procedures $(19,20)$, and an equal amount of protein samples was subjected to SDS-PAGE. The separated proteins were transferred to PVDF membranes (Bedford, MA, USA) and then incubated with primary antibodies overnight at $4^{\circ} \mathrm{C}$. After that, the membranes were incubated with a secondary antibody. Protein bands were visualized using an enhanced chemiluminescence detection kit (Daejon, Korea) and a LAS-4000 Imager (Tokyo, Japan).

Real Time-Polymerase Chain Reaction (RT-PCR). Real-time PCR analysis was performed according to our previously published procedures (21). Primers for real-time PCR were purchased from Bioneer (Daejeon, Korea): human AGR2: sense, 5'-GGTG GGTGAGGAAATCCAG-3'; antisense, 5'-GTAGGAGAGGGCC
ACAAGG-3'; human ADAMTS6: sense, 5'- ATC ACT CGA ACT GGC AGT GG-3'; antisense, 5'-GTC TTT GGA CAC CTC CAG CA-3'; human VEGFA: sense, 5'- GAG CCT TGC CTT GCT GCT CTA C-3'; antisense, 5'-CAC CAG GGT CTC GAT TGG ATG-3'; human $\beta$-actin: sense, 5'-AGC ACA ATG AAG ATC AAG AT-3'; antisense 5'-TGT AAC GCA ACT AAG TCA TA-3'.

Transfection of siRNAs. RNA interference of AGR2 (siAGR2\#1,1003498; siAGR2\#2,1003505) and ADAMTS6 (siADAMTS6\#1, 1002483; siADAMTS6\#1, 1002486) as well as the negative control siRNA (catalog number SN-1002), were synthesized by Bioneer (Daejeon, Korea). The cells were transfected with $20 \mathrm{nM}$ siRNA duplexes using Lipofectamine RNAiMAX (Invitrogen), according to the manufacturer's instructions. The cells were post-transfected at the indicated times and harvested for further analysis.

Sulforhodamine B assay. PC9-Gef cells were transfected with the control or AGR2 siRNA for $48 \mathrm{~h}$, and then $2 \times 10^{4}$ cells $/ \mathrm{ml}$ cells were seeded in 96-well plates with the indicated concentrations of gefitinib. After $72 \mathrm{~h}$ of treatment, the cells were fixed with $10 \%$ trichloroacetic acid (TCA) solution and cell proliferation was examined by the sulforhodamine B (SRB) assay and further analyzed as previously described (19). The ratios of cell proliferation were calculated using the following formula: cell proliferation $(\%)=100 \times$ $\left[\left(\mathrm{X}_{\text {treated }}-\mathrm{X}_{\text {zero day }}\right) /\left(\mathrm{X}_{\text {control }}-\mathrm{X}_{\text {zero day }}\right)\right]$, where $\mathrm{X}$ is the average absorbance. The $\mathrm{IC}_{50}$ values were calculated by using TableCurve 2D v5.01 (Systat Software Inc., San Jose, CA, USA).

Transwell invasion and migration assays. The cells were posttransfected with siAGR2 or siRNA control for $48 \mathrm{~h}$, and then they were further analyzed using cell migration and invasion assays, as described previously (22). Briefly, the invasion assay was carried out in 24 -well Transwell plates $(8.0 \mu \mathrm{m}$ pore size membranes, Corning, NY, USA) for $48 \mathrm{~h}$. The upper surface of the membrane was coated with Matrigel (BD Biosciences, San Jose, CA, USA) and the lower one was covered with $0.2 \%$ gelatin (Sigma Aldrich, St. Louis, MO, USA). Matrigel was not used in the case of the migration assay. After removing the non-invaded and non-migrated cells, the invaded and migrated cells on the lower side of membranes were fixed with $4 \%$ paraformaldehyde, and then stained with $0.5 \%$ crystal violet (Sigma-Aldrich). The cells were photographed using an inverted phased contrast light microscope and counted by the ImageJ application. 
Colony formation assay. The cells were post-transfected with siAGR 2 or siRNA control for $48 \mathrm{~h}$. Colony formation analysis was performed according to our previously published procedures (23). In brief, following post-transfection with siAGR 2 or siRNA control for $48 \mathrm{~h}, 500$ cells were seeded in 6-well plates or 12-well plates for about two weeks. The media with or without Gefitinib were changed every four days. After about 10-14 days, cells were stained by Crystal Violet and counted by the ImageJ application.

Immunocytochemistry. Immunocytochemistry analysis was performed according to our previously published procedures (24). In brief, cells were seeded on cover slips in dishes. After treatment with YD at indicated concentrations for $24 \mathrm{~h}$, the cells were fixed with $4 \%$ paraformaldehyde for $10 \mathrm{~min}$. The fixed cells were blocked with $1 \%$ BSA in PBS containing $0.1 \%$ Tween 20 for $30 \mathrm{~min}$ at $25^{\circ} \mathrm{C}$. The cells were incubated with a primary antibody at $4^{\circ} \mathrm{C}$ overnight. After that, the cells were incubated with a secondary antibody conjugated to Alexa 488 (Invitrogen) for $2 \mathrm{~h}$ at $25^{\circ} \mathrm{C}$. The nuclei were stained by DAPI $(0.5 \mu \mathrm{g} / \mathrm{ml})$. Ultimately, the images were obtained using a Zeiss ApoTome microscope (Csrl Zeiss, Jena, Germany).

Immunohistochemistry. Tumor immunohistochemistry analysis was performed according to our previously published procedures $(22$, 23). In brief, sections of the embedded specimens were deparaffinized, rehydrated and subjected to antigen retrieval. The sections were incubated overnight with an AGR2 antibody and detected using the LSAB ${ }^{\mathrm{TM}}+$ System-HRP kit (Glostrup, Denmark) and then counterstained with hematoxylin. Ultimately, the stained sections were observed and captured by using Vectra 3.0 Automated Quantitative Pathology Imaging System (PerkinElmer, Waltham, MA, USA).

Ex vivo biochemical analysis of tumors. The tumors were homogenized and protein concentrations were calculated, and aliquots were stored at $-80^{\circ} \mathrm{C}$ and used according to our previously published procedures (23).

Microarray expression analysis. Microarray expression analysis was performed according to our previously published procedures $(22,23)$.

Exosome isolation. Total exosomes were collected by Invitrogen Total Exosome Isolation Reagent from Invitrogen (catalog number 4478359), following the manufacturer's instructions.

Statistical analysis. The data are presented as the mean \pm SD Statistical significance $(* p<0.05, * * p<0.01, * * * p<0.001)$ was assessed using Student's t test. All statistical tests were two-tailed unpaired.

\section{Results}

AGR2 expression is upregulated in gefitinib-resistant NSCLC cells. In our previous study, a cDNA array was employed to identify differentially expressed genes in three types of NSCLC cells: PC9, PC9-Gef, and PC9-Gef treated with YD (25). The data showed that AGR2 expression was upregulated in PC9-Gef cells compared to PC9 cells, and the expression of AGR2 was effectively suppressed by the treatment of YD. In the present study, these findings were further confirmed by in vitro cell cultures and ex vivo tissue analysis. As shown in Figure 1A, the AGR2 mRNA levels in PC9-Gef cells were approximately five-fold higher than those in PC9 cells. The AGR2 protein was hardly detected in the parental PC9 cells, but it was significantly overexpressed in PC9-Gef-resistant cells (Figure 1B). Previous reports have shown that intracellular AGR2 can induce the growth of cancer cells and AGR2 can also be detected extracellularly in the blood and urine of prostate cancer patients (26) (27). Therefore, we determined whether the extracellular levels of AGR2 are different between PC9 and PC9-Gef cells by using exosomal samples in the extracellular environment. The secretion of AGR2 mRNA was higher in PC9-Gef cells compared to the parental PC9 cells (Figure 1C). In addition, utilizing tumor tissues obtained in our previous study, we also found that AGR2 expression was upregulated in PC9-Gef cells compared to PC9 cells in vivo at both the mRNA (Figure 1D) and protein (Figure 1E) levels. Consistently, a higher expression of AGR2 in PC9-Gef cells and tumors was also found by immunocytochemistry (Figure $1 F$ and $G$ ). Taken together, these findings suggested that AGR2 is a potential candidate biomarker for the acquired resistance of NSCLC cells to Gef.

AGR2 expression is associated with proliferation, drug resistance, and metastasis of gefitinib-resistant NSCLC cells. To further evaluate the function of AGR2 in Gef-resistant cells, the PC9-Gef cells were transiently transfected with an siRNA control (siCTL) or siRNA AGR2 (siAGR2). First, we selected the efficient siRNA from different sets of siRNA AGR2 to obtain significant depletion of AGR2 expression in PC9-Gef cells. The set \#2 of siAGR2 was shown to effectively suppress the expression of the AGR2 mRNA and protein (Figure 2A and B), and thus this set was selected and used for further study. The knockdown of AGR2 (siAGR2) resulted in a notable decrease in colony formation by the PC9-Gef cells (Figure 2C). Silencing of AGR2 also significantly inhibited the invasion (Figure 2D) and migration (Figure 2E) of PC9-Gef cells. Moreover, the depletion of AGR2 affected the sensitivity of PC9-Gef cells to Gef. Compared to the siCTL-transfected PC9-Gef cells, treatment of siAGR2-transfected PC9-Gef cells with $5 \mu \mathrm{M}$ Gef efficiently suppressed colony formation, indicating restoration of the sensitivity to Gef (Figure 2F). The anti-proliferative activity of Gef in the PC9-Gef cells was also recovered by the silencing of AGR2 with an $\mathrm{IC}_{50}$ of $0.68 \mu \mathrm{M}$ in PC9-Gef siAGR2 cells compared to the $\mathrm{IC}_{50}$ of $4.34 \mu \mathrm{M}$ in PC9-Gef siCTL cells (Figure 2G).

AGR2 and ADAMTS6 form a negative feedback loop and affect VEGFA expression. To further identify the downstream targets of AGR2 and its functions in cancer cells, a cDNA microarray was performed using siAGR2-transfected PC9-Gef cells. As 
shown in Table I, several genes were up-regulated in siAGR2transfected PC9-Gef cells. ADAMTS6 was among the highly up-regulated genes and this was additionally confirmed by RTPCR analysis (Figure 3A). We further investigated the association between AGR2 and ADAMTS6 in the PC9-Gef cells. Initially, the efficient siRNAs for ADAMTS6 were selected by RT-PCR analysis for further study (siADAMTS6 \#1 was selected in this study) (Figure 3B). Previous studies have shown that both AGR2 and ADAMTS family members are strongly related to angiogenesis $(28,29)$. Therefore, we analyzed whether there is a relationship among AGR2, ADAMTS6, and angiogenesis. We found that the knockdown of ADAMTS6 up-regulated AGR2 mRNA (Figure 3C) and protein (Figure 3D) expression, indicating the negative correlation between AGR2 and ADAMTS6. In addition, silencing of AGR2 suppressed the expression of VEGFA (an angiogenesis biomarker) in PC9-Gef cells (Figure 3E). These results suggested that AGR2 is associated with the angiogenic process in cancer cells. However, the precise mechanism through which AGR2 regulates angiogenesis needs to be further analyzed in detail.

Yuanhuadine affects AGR2, ADAMTS6, and VEGFA expression. Natural products are still considered as important sources in drug discovery and development (30-32) and our previous studies have indicated that yuanhuadine (YD), a natural product-derived antitumor agent, could significantly suppress the growth of acquired drug-resistant NSCLC cells and overcome the EGFR-TKIs resistance in NSCLC cells both in vitro and in vivo $(22,23)$. Therefore, we further investigated whether YD overcomes drug resistance by modulating AGR2 in EGFR-mutant NSCLC cells. Overexpression of AGR2 mRNA and protein in PC9-Gef cells were significantly suppressed by YD treatment in a concentration-dependent manner (Figure 4A and B). In addition, immunocytochemical analysis also suggested that YD treatment suppressed overexpression of cytoplasmic AGR2 in the PC9-Gef cells in a concentration-dependent manner (Figure 4C). Similarly, the expression of AGR2 in tumor tissues obtained from our previous study on the anti-tumor activity of YD (25) was also found to be suppressed by YD treatment by both western blot and immunohistochemical analysis (Figure 4D and E).

As depicted in Figure 3, we found that expression of AGR2 was negatively regulated by ADAMTS6. The expression of ADAMTS6 mRNA was up-regulated in YDtreated PC9-Gef cells (Figure 5A) and tumor tissues (Figure 5B). However, the expression of VEGFA mRNA was downregulated in YD-treated PC9-Gef cells (Figure 5C) and tumor tissues (Figure 5D). Taken together, these results that the axis of AGR2/ADAMTS6/VEGFA may be involved in the acquired EGFR-TKI drug resistance of NSCLC cells and targeting this axis will be a potential strategy to overcome the resistance in NSCLC cells.

\section{Discussion}

The first-generation EGFR-TKIs, such as gefitinib, have been used as first-line or second-line therapy for advanced EGFR-mutant NSCLCs. However, the sequential drug resistance has still been inevitable. Therefore, various studies have attempted to elucidate the mechanisms of resistance to overcome or delay the resistance of NSCLC cells $(22,23$, $25,33-45)$. In addition, recent comprehensive proteomic technologies display a great opportunity to investigate novel clinically relevant oncogenic pathways that may have been over-looked by cancer gene screens $(46,47)$. AGR2, one of these recently discovered oncogenes related to $\mathrm{p} 53$, is directly involved in malignant transformation and is able to act as a survival factor through drug resistance (48). However, the modulation of AGR2 expression and its potential mechanisms in drug resistance of EGFR-mutant NSCLCs have not yet been precisely investigated.

Herein, for the first time, we found that the levels of AGR2 are highly associated with Gef-resistance of EGFRmutant NSCLC cells. Similarly, AGR2 was shown to contribute to drug resistance in breast cancer (49) and pancreatic cancer (50), and high expression of AGR2 in lung cancer has been also considered to be predictive of poor survival (9). Additionally, AGR2 silencing has been shown to decrease chemotherapy resistance and inhibit cell invasion and migration of pancreatic cancer cells (50). In the present study, we also observed that knockdown of AGR2 suppressed cell proliferation, colony formation, and migration of PC9-Gef cells, which are Gef-resistant EGFR-mutant NSCLC cells (Figure 2). In particular, silencing of AGR2 resulted in the recovery of the sensitivity of Gef-resistant PC9-Gef cells to Gef. These findings suggest that suppression of AGR2 may play a critical role in the regulation of cancer progression and development, as well as acquired drug resistance in lung cancer cells.

Figure 1. Up-regulation of AGR2 in PC9-Gef cells and xenograft tumors. (A), (B) The cells were lysed and the mRNA and protein expression of $A G R 2$ were determined by real-time $P C R(A)$ and western blot analysis $(B)$, respectively. $(C)$ Total exosomes from PC9 and PC9Gef cells were collected and exosomal AGR2 expression was evaluated by real-time PCR. (D), (E) PC9 and PC9-Gef tumor tissues were obtained from our previous study and analyzed by real-time PCR $(D)$ and western blot analysis (E), respectively. (F) PC9 and PC9-Gef cells stained with AGR2 and DAPI. (G) Immunohistochemical analysis for $A G R 2$ was performed using an antibody against AGR2. For (A-E), $\beta$ actin was used as a control. For $(A),(C)$, and $(D)$, data are presented as the mean fold changes $\pm S D$ relative to the control. For $(F)$ and $(G)$, scale bars, $100 \mu \mathrm{m} .{ }^{*} p<0.05,{ }^{* *} p<0.01,{ }^{* *} p<0.001$. 
A

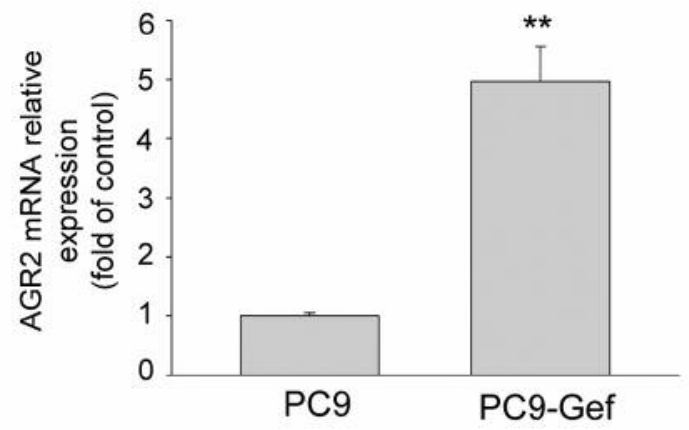

C

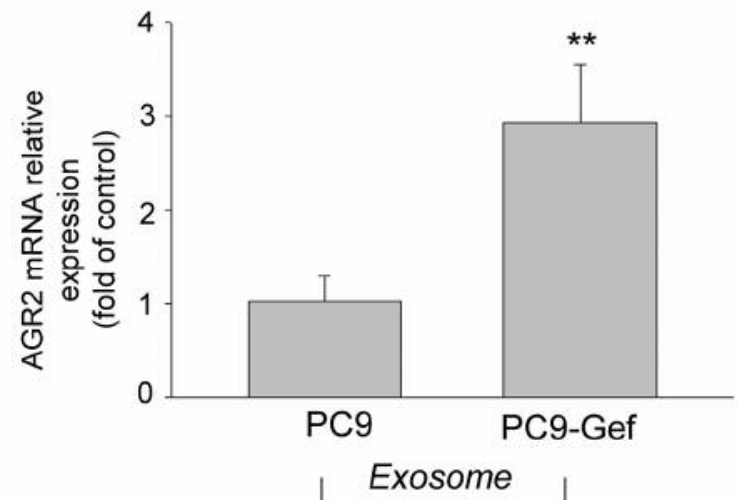

E
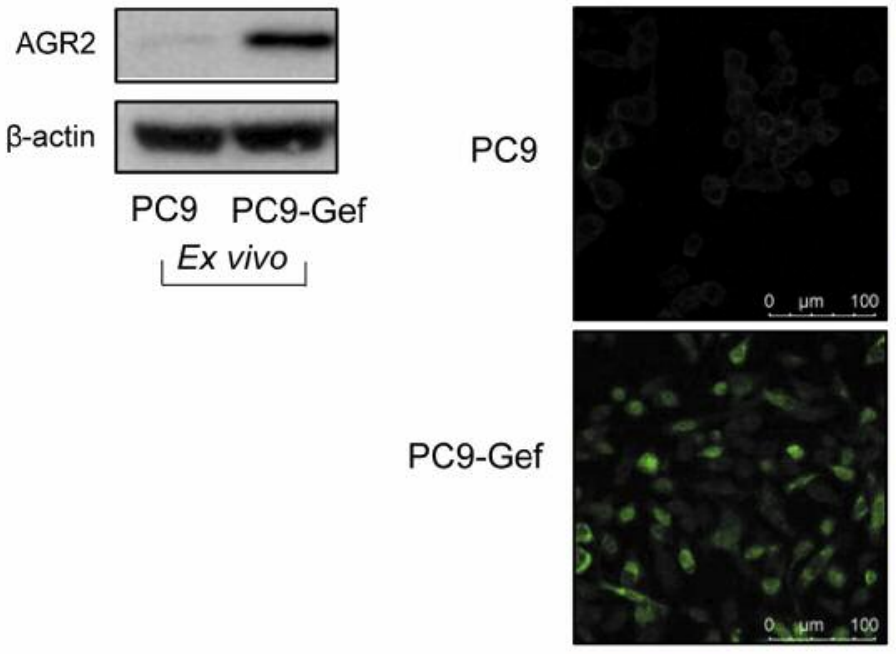

G

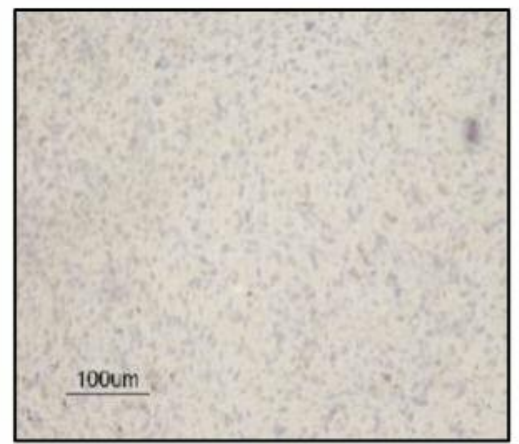

PC9
B

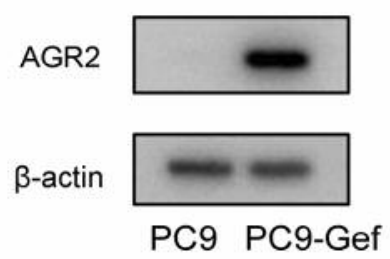

D

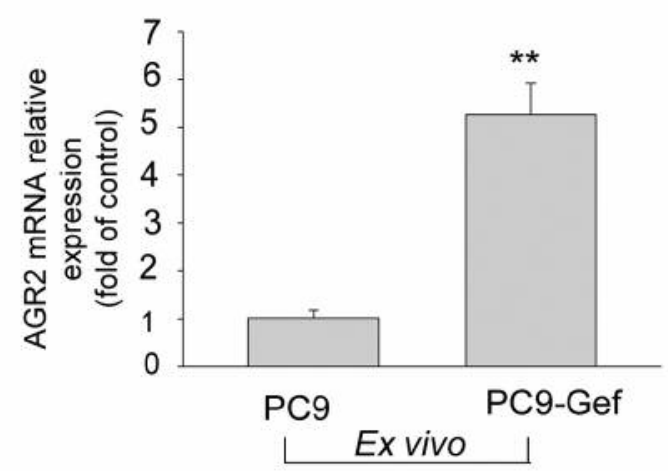

DAPI

Merge
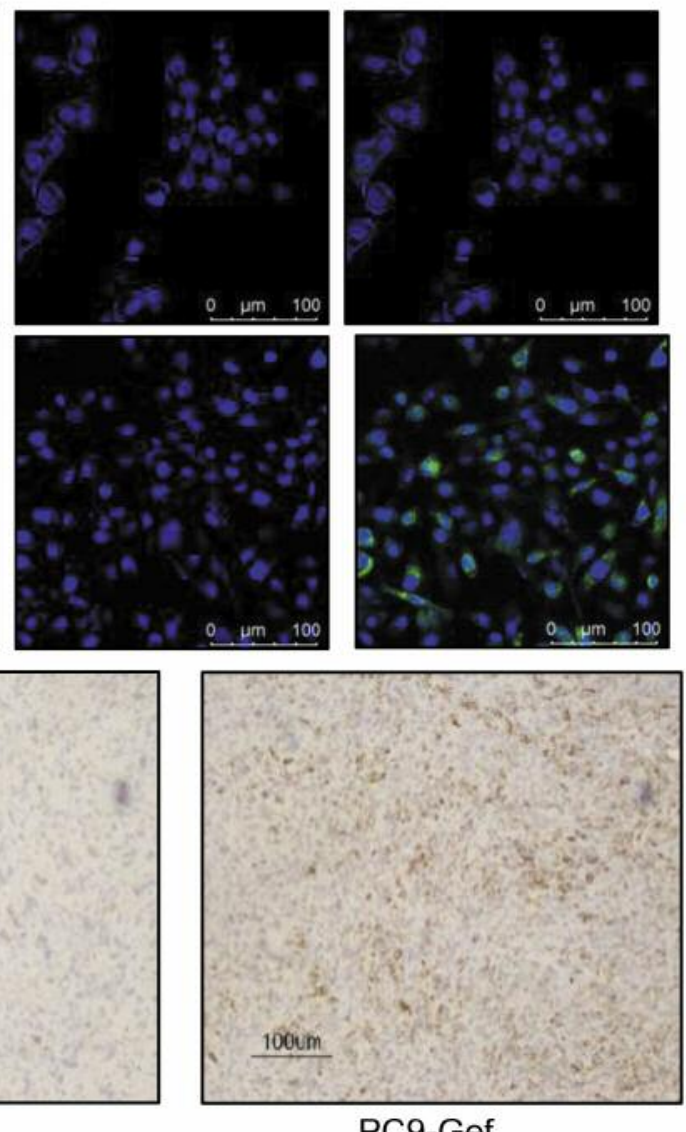

PC9-Gef 


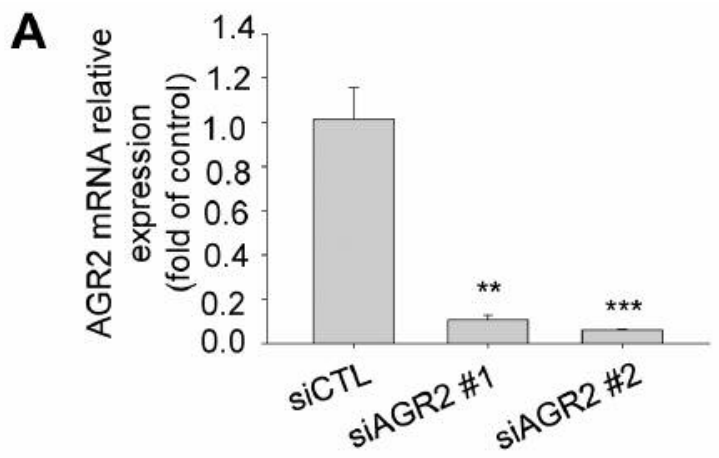

B

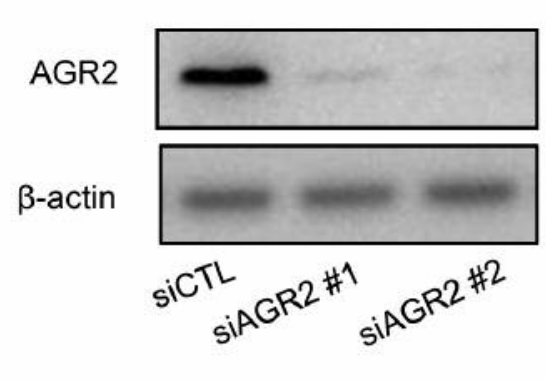

C

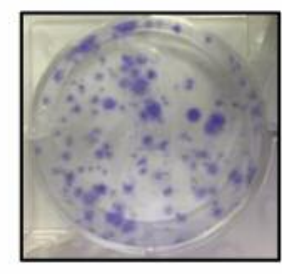

siCTL

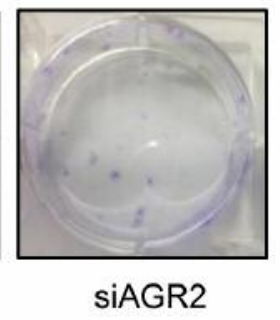

D

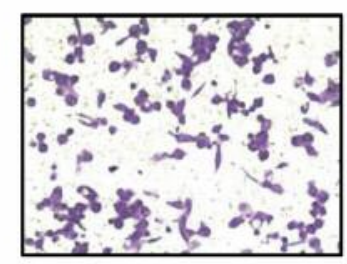

SiCTL
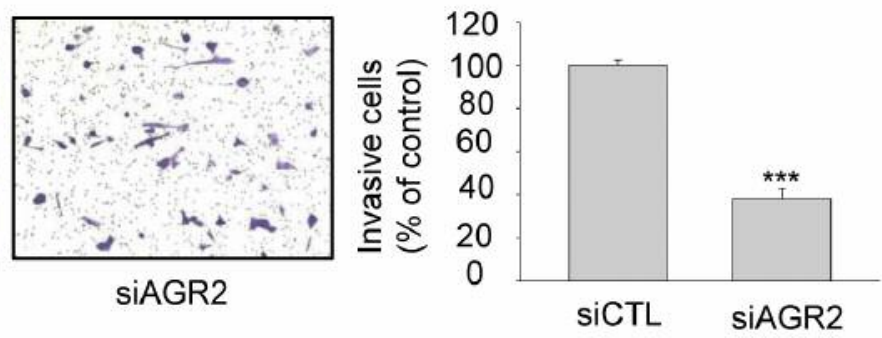

E
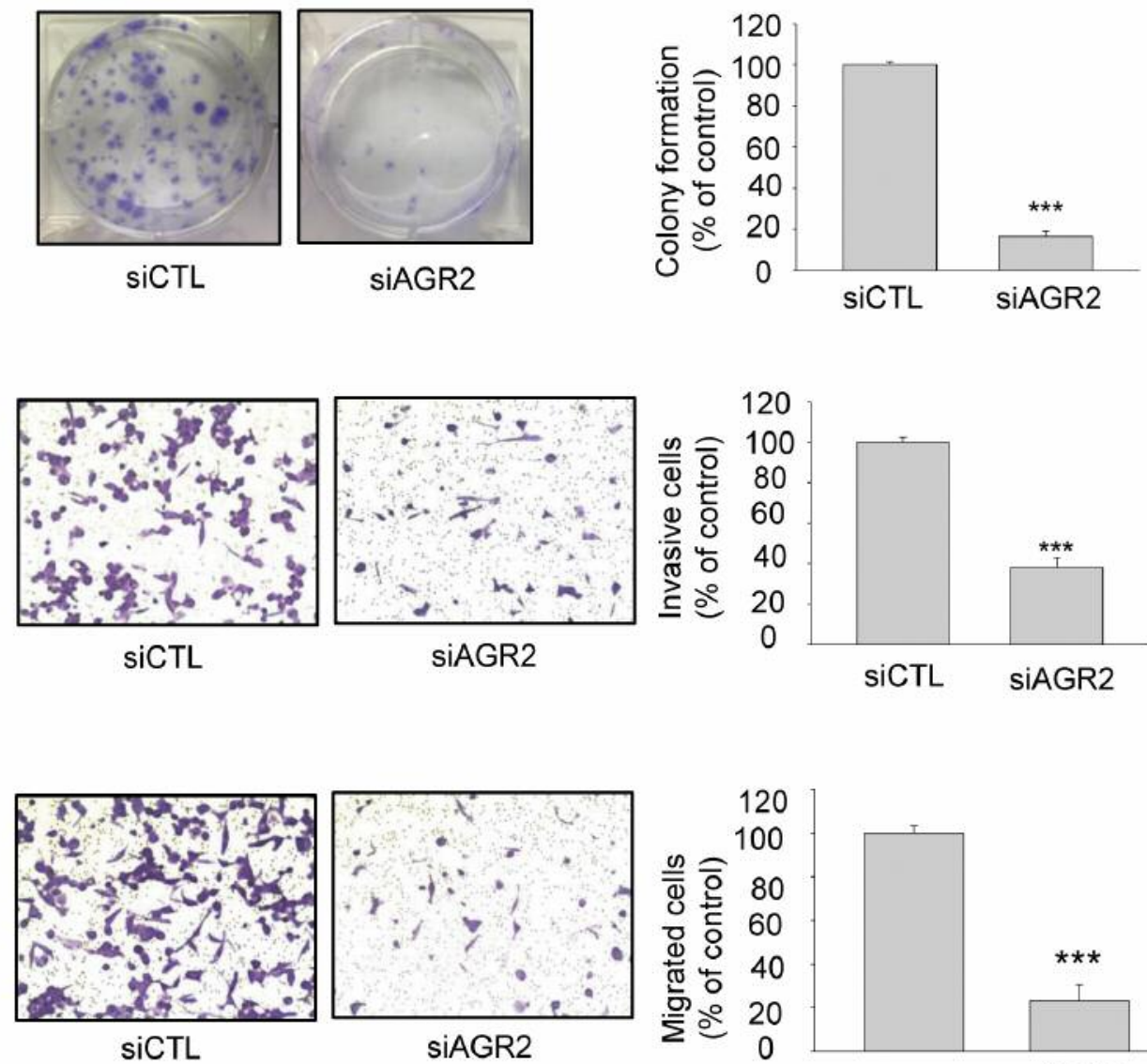

F

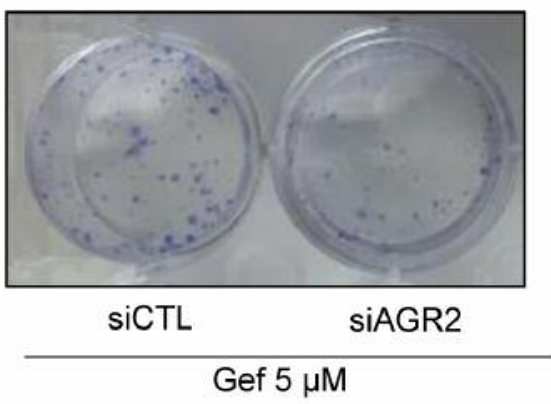




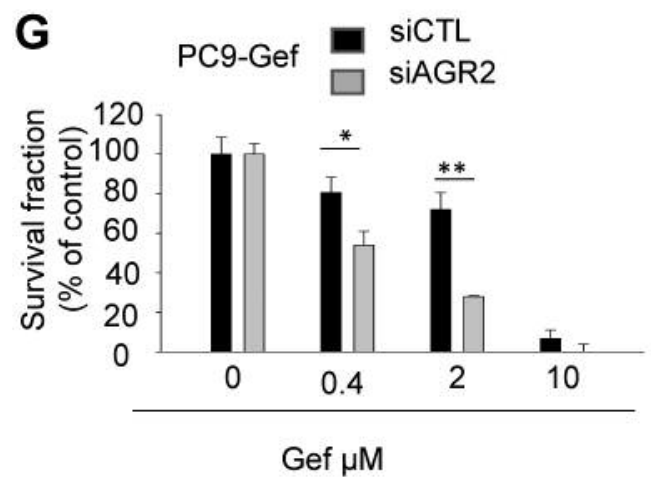

\begin{tabular}{|c|c|}
\hline Cell lines & IC50_Gef $(\mu \mathrm{M})$ \\
\hline $\begin{array}{c}\text { PC9_Gef } \\
\text { siCTL }\end{array}$ & 4.34 \\
\hline $\begin{array}{c}\text { PC9_Gef } \\
\text { siAGR2 }\end{array}$ & 0.68 \\
\hline
\end{tabular}

Figure 2. AGR2 modulates the malignant characteristics and gefitinib sensitivity in PC9-Gef cells. (A), (B). Confirmation of AGR2 silencing at the mRNA (A) and protein level (B). (C-F) PC9-Gef cells were transfected with either control siRNA or AGR2 siRNA \#2 for 48 h and then cultured for the colony formation assay in normal media $(C)$ or media with $5 \mu M$ Gefitinib $(F)$. Similarly, the PC9-Gef cells transfected with siAGR2 were analysed by an invasion $(D)$ and migration assay $(E)$. $(G)$ PC9-Gef cells were transfected with the control or AGR2 siRNA \#2 for $48 \mathrm{~h}$ and then treated with different concentrations of Gef. The SRB experiment was carried out as described in the Materials and Methods to evaluate cell viability. $\beta$-actin was used as a control. Data are presented as the mean fold changes \pm SD relative to control. $* p<0.05, * * p<0.01, * * * p<0.005$.

Natural products have played an important role in the discovery of anticancer drugs (51). In our previous studies, we have found that yuanhuadine (YD), a daphnane-type diterpenoidal anti-tumor agent from the flowers of Daphne genkwa, can effectively suppress the growth of EGFR-TKIresistant NSCLC cells $(21-23,52)$. Therefore, we further investigated whether the regulation of AGR2 can modulate EGFR-TKI resistance and whether resistance can be overcome by treating NSCLC cells with YD. The suppressive effect of YD on AGR2 expression in PC9-Gef cells and tumor tissues from a xenograft mouse model may be in part associated with the restoration of the sensitivity of NSCLC cells to EGFR-TKIs (Figure 4). These findings may lead to a new strategy to overcome resistance or effectively suppress the growth of EGFR-TKI-resistant NSCLC cells by either YD alone or through a combination of YD and AGR2 depletion.

Recent studies have suggested that the association of AGR2 with chemotherapy resistance involves the ERK/Akt pathway or some non-coding RNAs $(49,50)$. In this line, we further investigated novel downstream targets of AGR2 by employing a cDNA microarray and knockdown of AGR2. ADAMTS6 expression was significantly up-regulated by the knockdown of AGR2, while the knockdown of ADAMTS6 was also able to up-regulate the expression of AGR2, suggesting a negative feedback loop between AGR2 and ADAMTS6 (Table I and Figure 3). Although the integrative network between AGR2 and ADAMTS6 has been reported in Alzheimer's disease, a negative feedback loop between AGR2 and ADAMTS6 in NSCLC cells is reported for the first time in this study. Interestingly, previous reports have indicated that elevated ADAMTS6 expression could suppress tumor progression and serve as a prognostic marker in human cancer, whereas the depletion of ADAMTS6 stimulated cell migration and tumorigenesis (14). Consistently, we also found that knockdown of AGR2 suppressed VEGFA mRNA expression, but knockdown of ADAMTS6 enhanced VEGFA mRNA expression, which is highly related to chemotherapy resistance $(53,54)$, suggesting that AGR2 directly affects the expression of VEGFA, while ADAMTS6 might affect VEGF expression through AGR2 in drug resistance of mutant NSCLC cells. Finally, we further determined the effects of YD on this ADAMTS6-AGR2 -VEGFA axis and found that YD could upregulate ADAMTS6 and downregulate AGR2 expression leading to suppressed VEGFA expression in NSCLC cells.

\section{Conclusion}

Taken together, we demonstrated that AGR2 is highly correlated with the acquired drug resistance of EGFR-mutant NSCLC cells to EGFR-TKI by stimulating cell proliferation, colony formation, and migration through the modulation of ADAMTS6 and VEGFA expression. In addition, the antitumor activity of YD in NSCLC cells is in part associated with the suppression of AGR2 and VEGFA and the upregulation of ADAMTS6 expression. Therefore, these findings may provide attractive targets for overcoming drugresistance of EGFR-mutant NSCLC cells.

\section{Conflicts of Interest}

The Authors declare no conflict of interest regarding this study.

\section{Authors' Contributions}

T.-T.-T.L. \& D.-H.B designed and carried out most of the experiments, assisted by D.K., and R.H. H.J.P. discussed the 
A

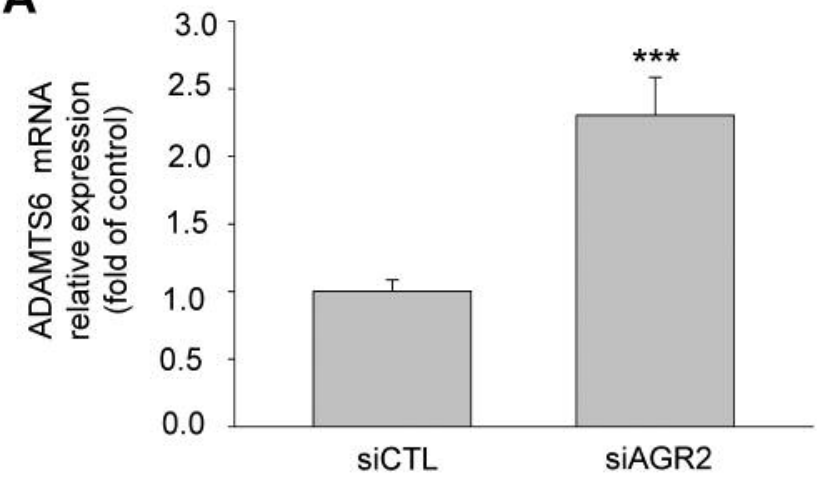

C

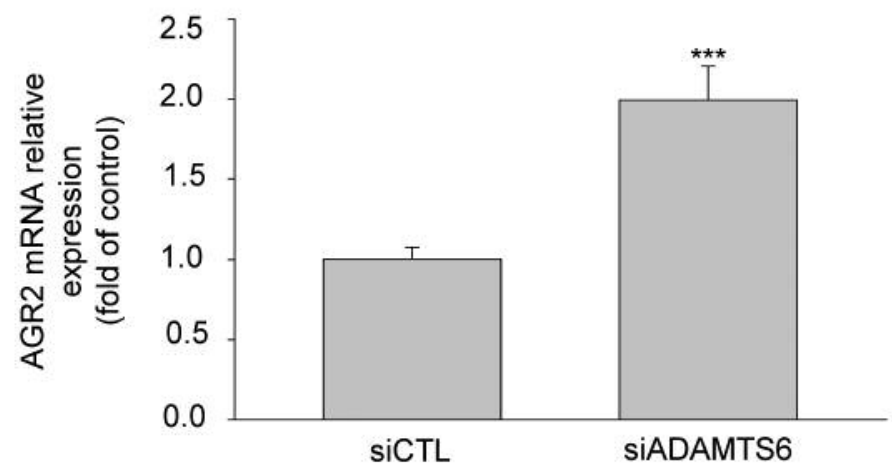

B

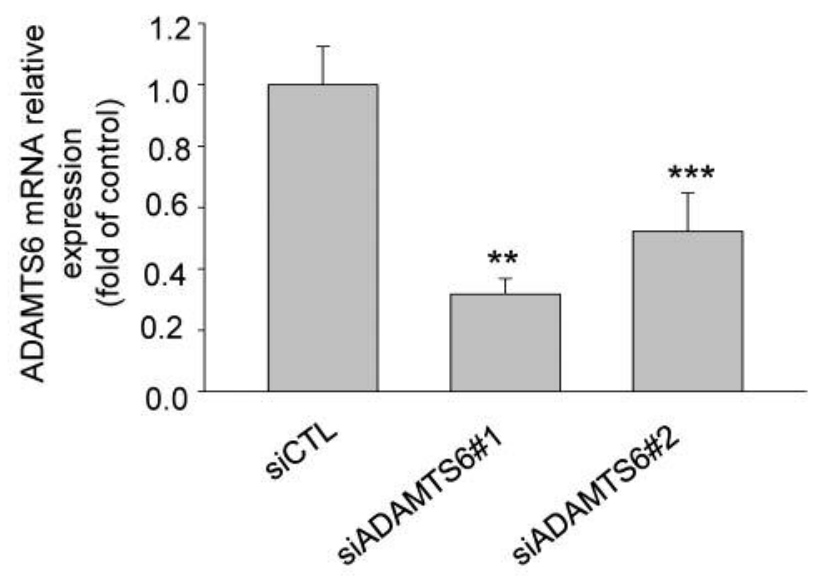

D

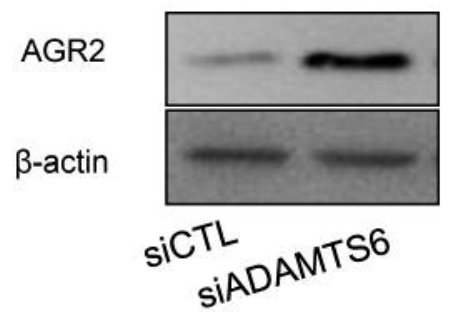

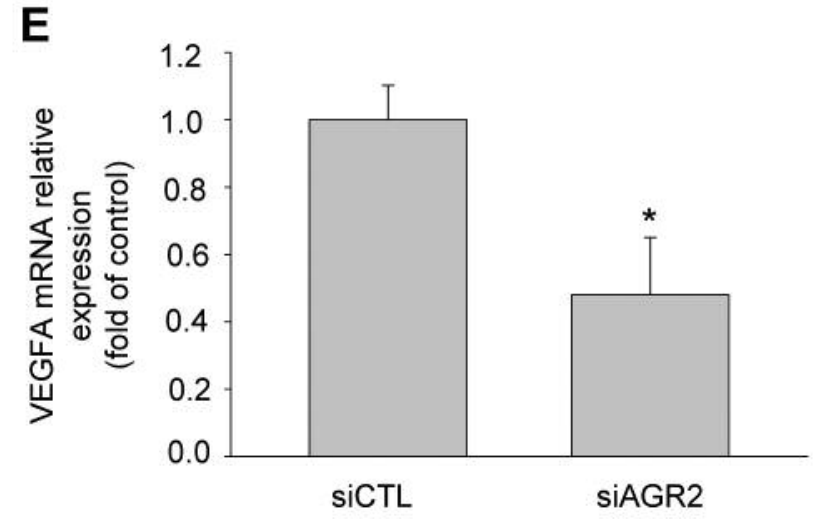

Figure 3. Effects of AGR2 and ADAMTS6 on VEGFA expression in PC9Gef cells. (A) PC9-Gef cells were transfected with control or AGR2 siRNA \#2 for $48 \mathrm{~h}$, and real-time PCR was employed for the determination of ADAMTS6 mRNA expression. (B) PC9-Gef cells were transfected with negative control siRNA or siADAMTS6 \#1 or siADAMTS6 \#2, and RT$P C R$ was employed to evaluate the ADAMTS6 mRNA expression. $(C)$, (D), PC9-Gef cells were transfected with the control or ADAMTS6 siRNA $\# 1$ for $48 \mathrm{~h}$, and $m R N A$ and protein expression was analyzed by real-time $P C R$ and western blot. The AGR2 mRNA (C) and protein $(D)$ expression were determined. (E) PC9-Gef cells were transfected with the control SiRNA or AGR2 siRNA \#2 for $48 \mathrm{~h}$, and real-time PCR was employed for the determination of VEGFA mRNA expression. $\beta$-actin was used as a control. Data are presented as the mean fold changes $\pm S D$ relative to control. $* p<0.05, * * p<0.01, * * * p<0.005$. results. T.-T.-T.L. \& D.-H.B wrote the initial draft of the manuscript. S.K.L. designed and supervised the work and edited the manuscript.

\section{Acknowledgements}

This research was supported by Basic Science Research Program through the National Research Foundation of Korea (NRF) funded by the Ministry of Education (2019 R1I1A1A01060558).

\section{References}

1 Zhao DP, Yang CL, Zhou X, Ding JA and Jiang GN: Association between clptm1l polymorphisms (rs402710 and rs401681) and lung cancer susceptibility: Evidence from 27 case-control studies. Mol Genet Genomics 289(5): 1001-1012, 2014. PMID: 24907075. DOI: 10.1007/s00438-014-0868-7

2 Pao W, Miller VA, Politi KA, Riely GJ, Somwar R, Zakowski MF, Kris MG and Varmus $\mathrm{H}$ : Acquired resistance of lung 


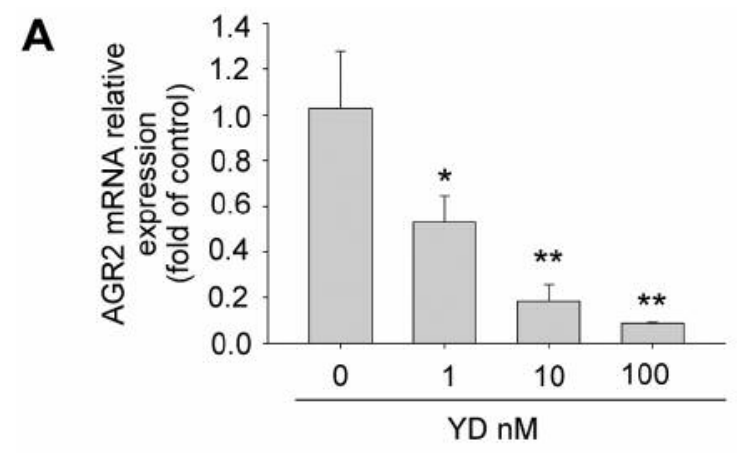

B
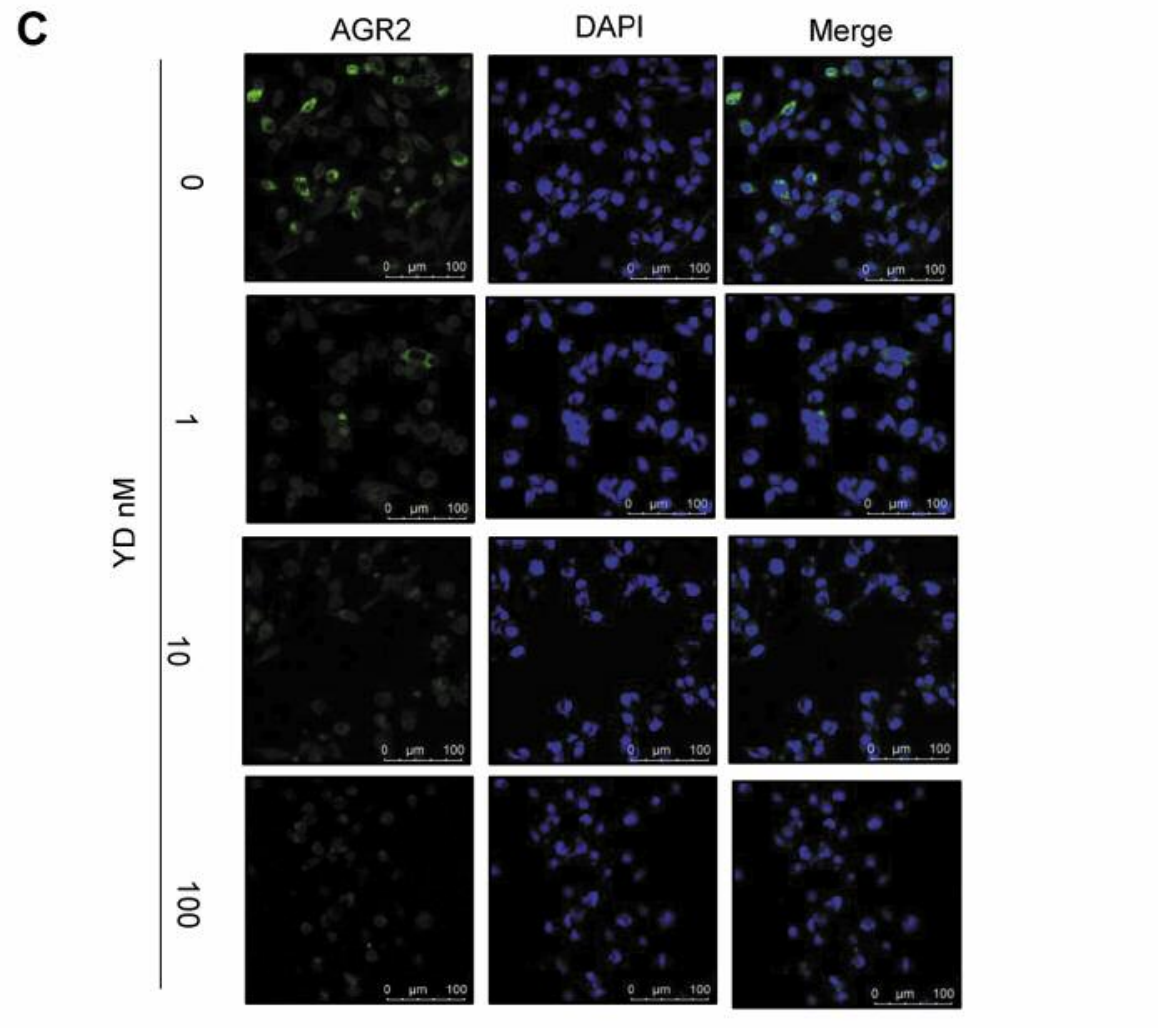

D

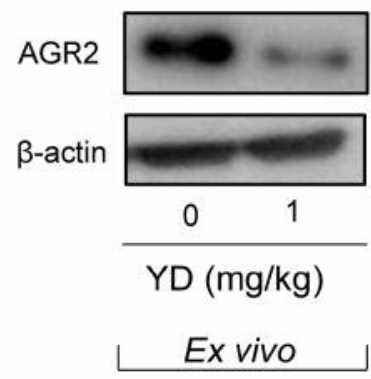

E

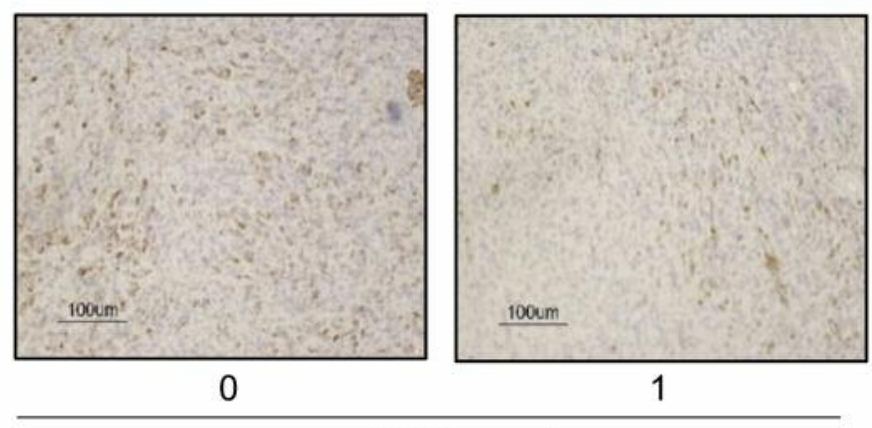

$\mathrm{YD}(\mathrm{mg} / \mathrm{kg})$

Figure 4. YD suppresses AGR2 expression in PC9-Gef cells and xenograft tumors. (A), (B) PC9-Gef cells treated with YD for $24 \mathrm{~h}$ and mRNA (A) and protein expression (B) of AGR2 were determined by real-time PCR and western blot analysis, respectively. (C) PC9-Gef cells were treated with $Y D$ for $24 \mathrm{~h}$, and cells were then stained with an AGR2 antibody and DAPI for immunocytochemical analysis. (D) The levels of AGR2 protein expression in cells treated with $Y D$ were analyzed in xenograft tissues by western blot analysis, as described in the Materials and Methods. (E). Immunohistochemical analysis of excised tumor tissues treated with YD for AGR2 protein expression. (A), (B), (D), $\beta$-actin was used as a control. Data are presented as the mean fold changes $\pm S D$ relative to the control. For $(C)$ and $(E)$, scale bars, $100 \mu m$. ${ }^{*} p<0.05, * * p<0.01, * * * p<0.005$. 

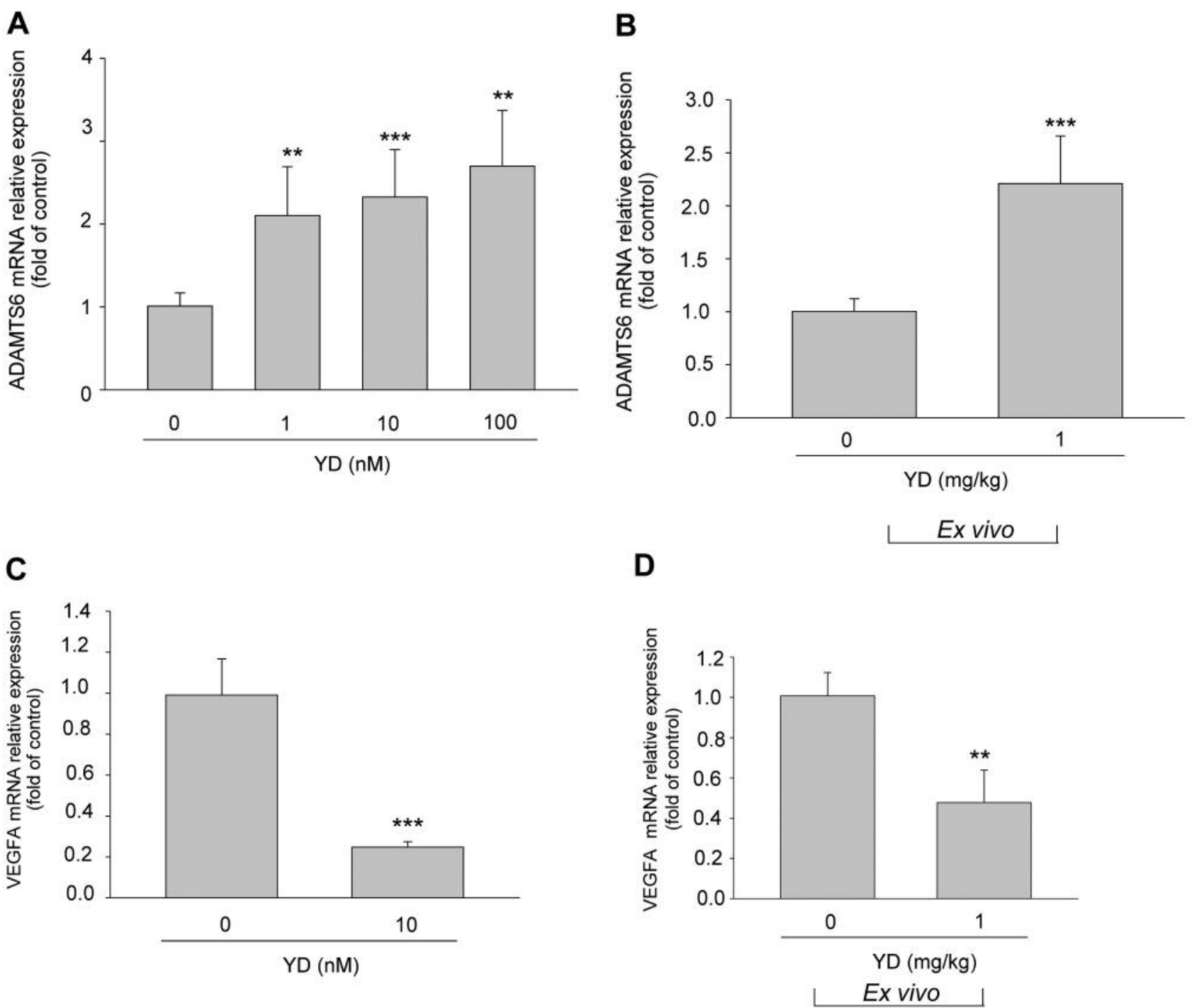

Figure 5. YD upregulated ADAMTS6 and suppressed VEGFA in PC9 Gef cells and xenograft tumors. (A), (C) PC9-Gef cells were treated with YD for $24 \mathrm{~h}$, and real-time PCR was employed for determining ADAMTS6 mRNA expression (A) and VEGFA mRNA expression (C). (B), (D) The mRNA levels of ADAMTS6 $(B)$ and VEGFA (D) were analyzed in the xenograft tissues treated with YD by real-time PCR, as described in the Materials and Methods. $\beta$-actin was used as a control. Data are presented as the mean fold changes $\pm S D$ relative to control. $* p<0.05, * * p<0.01, * * * p<0.005$.

adenocarcinomas to gefitinib or erlotinib is associated with a second mutation in the egfr kinase domain. PLoS Med 2(3): e73, 2005. PMID: 15737014. DOI: 10.1371/journal.pmed.0020073

3 Aberger F, Weidinger G, Grunz $\mathrm{H}$ and Richter K: Anterior specification of embryonic ectoderm: The role of the xenopus cement gland-specific gene xag-2. Mech Dev 72(1): 115-130, 1998. PMID: 9533957. DOI: 10.1016/s0925-4773(98)00021-5

$4 \mathrm{Hu}$ Z, Gu Y, Han B, Zhang J, Li Z, Tian K, Young CYF and Yuan H: Knockdown of agr2 induces cellular senescence in prostate cancer cells. Carcinogenesis 33(6): 1178-1186, 2012. PMID: 22467239. DOI: $10.1093 /$ carcin/bgs141

5 Liu D, Rudland PS, Sibson DR, Platt-Higgins A and Barraclough R: Human homologue of cement gland protein, a novel metastasis inducer associated with breast carcinomas. Cancer Res
65(9): 3796-3805, 2005. PMID: 15867376. DOI: 10.1158/00085472.CAN-04-3823

6 Ramachandran V, Arumugam T, Wang H and Logsdon CD: Anterior gradient 2 is expressed and secreted during the development of pancreatic cancer and promotes cancer cell survival. Cancer Res 68(19): 7811-7818, 2008. PMID: 18829536. DOI: $10.1158 / 0008-5472 . C A N-08-1320$

7 Ondrouskova E, Sommerova L, Nenutil R, Coufal O, Bouchal P, Vojtesek B and Hrstka R: Agr2 associates with her2 expression predicting poor outcome in subset of estrogen receptor negative breast cancer patients. Ex Mol Pathol 102(2): 280-283, 2017. PMID: 28238761. DOI: 10.1016/j.yexmp.2017.02.016

8 Chevet E, Fessart D, Delom F, Mulot A, Vojtesek B, Hrstka R, Murray E, Gray T and Hupp T: Emerging roles for the pro- 
oncogenic anterior gradient-2 in cancer development. Oncogene 32: 2499, 2012. PMID: 22945652. DOI: 10.1038/onc.2012.346

9 Alavi M, Mah V, Maresh EL, Bagryanova L, Horvath S, Chia D, Goodglick L and Liu AY: High expression of agr2 in lung cancer is predictive of poor survival. BMC cancer 15: 655-655, 2015. PMID: 26445321. DOI: 10.1186/s12885-015-1658-2

10 Kelwick R, Desanlis I, Wheeler GN and Edwards DR: The adamts (a disintegrin and metalloproteinase with thrombospondin motifs) family. Genome Biol 16(1): 113-113, 2015. PMID: 26025392. DOI: 10.1186/s13059-015-0676-3

11 Kumar S, Rao N and Ge R: Emerging roles of adamtss in angiogenesis and cancer. Cancers 4(4): 1252-1299, 2012. PMID: 24213506. DOI: $10.3390 /$ cancers 4041252

12 Rocks N, Paulissen G, Quesada-Calvo F, Munaut C, Gonzalez M-LA, Gueders M, Hacha J, Gilles C, Foidart J-M, Noel A and Cataldo DD: Adamts-1 metalloproteinase promotes tumor development through the induction of a stromal reaction in vivo. Cancer Res 68(22): 9541-9550, 2008. PMID: 19010931. DOI: 10.1158/0008-5472.CAN-08-0548

13 Freitas VM, do Amaral JB, Silva TA, Santos ES, Mangone FR, Pinheiro JdJ, Jaeger RG, Nagai MA and Machado-Santelli GM: Decreased expression of adamts- 1 in human breast tumors stimulates migration and invasion. Mol Cancer 12(1): 2, 2013 PMID: 23289900. DOI: 10.1186/1476-4598-12-2

14 Xie Y, Gou Q, Xie K, Wang Z, Wang Y and Zheng H: Adamts6 suppresses tumor progression via the erk signaling pathway and serves as a prognostic marker in human breast cancer. Oncotarget 7(38): 61273-61283, 2016. PMID: 27542224. DOI: 10.18632/oncotarget.11341

15 Xiao WH, Qu XL, Li XM, Sun YL, Zhao HX, Wang S and Zhou $\mathrm{X}$ : Identification of commonly dysregulated genes in colorectal cancer by integrating analysis of rna-seq data and qrt-pcr validation. Cancer Gene Ther 22(5): 278-284, 2015. PMID: 25908452. DOI: $10.1038 /$ cgt.2015.20

16 Wierinckx A, Auger C, Devauchelle P, Reynaud A, Chevallier P, Jan M, Perrin G, Fevre-Montange M, Rey C, FigarellaBranger D, Raverot G, Belin MF, Lachuer J and Trouillas J: A diagnostic marker set for invasion, proliferation, and aggressiveness of prolactin pituitary tumors. Endocr Relat Cancer 14(3): 887-900, 2007. PMID: 17914117. DOI: 10.1677/ERC-07-0062

17 Porter S, Scott SD, Sassoon EM, Williams MR, Jones JL, Girling AC, Ball RY and Edwards DR: Dysregulated expression of adamalysin-thrombospondin genes in human breast carcinoma. Clin Cancer Res 10(7): 2429-2440, 2004.

18 Hong JY, Chung HJ, Lee HJ, Park HJ and Lee SK: Growth inhibition of human lung cancer cells via down-regulation of epidermal growth factor receptor signaling by yuanhuadine, a daphnane diterpene from daphne genkwa. J Nat Prod 74(10): 2102-2108, 2011. PMID: 21916433. DOI: 10.1021/np2003512

19 Bach DH, Kim SH, Hong JY, Park HJ, Oh DC and Lee SK: Salternamide a suppresses hypoxia-induced accumulation of hif$1 \alpha$ and induces apoptosis in human colorectal cancer cells. Mar Drugs 13(11): 6962, 2015. PMID: 26610526. DOI: 10.3390/ md13116962

20 Bach DH, Liu JY, Kim WK, Hong JY, Park SH, Kim D, Qin SN, Luu TT, Park HJ, Xu YN and Lee SK: Synthesis and biological activity of new phthalimides as potential anti-inflammatory agents. Bioorg Med Chem 25(13): 3396-3405, 2017. PMID: 28478865. DOI: $10.1016 /$ j.bmc.2017.04.027
21 Kim D, Bach DH, Fan YH, Luu TTT, Hong JY, Park HJ and Lee SK: Axl degradation in combination with egfr-tki can delay and overcome acquired resistance in human non-small cell lung cancer cells. Cell Death Dis 10(5): 361, 2019. PMID: 31043587. DOI: 10.1038/s41419-019-1601-6

22 Bach DH, Luu TT, Kim D, An YJ, Park S, Park HJ and Lee SK: Bmp4 upregulation is associated with acquired drug resistance and fatty acid metabolism in EGFR-mutant non-small-cell lung cancer cells. Mol Ther Nucleic Acids 12: 817-828, 2018. PMID: 30153566. DOI: 10.1016/j.omtn.2018.07.016

23 Bach DH, Kim D, Bae SY, Kim WK, Hong JY, Lee HJ, Rajasekaran N, Kwon S, Fan Y, Luu TT, Shin YK, Lee J and Lee SK: Targeting nicotinamide n-methyltransferase and mir-449a in egfr-tki-resistant non-small-cell lung cancer cells. Mol Ther Nucleic Acids 11(455-467, 2018. PMID: 29858080. DOI: 10.1016/j.omtn.2018.03.011

24 Bae SY, Park HJ, Hong J-Y, Lee H-J and Lee SK: Downregulation of serpinb2 is associated with gefitinib resistance in non-small cell lung cancer and enhances invadopodia-like structure protrusions. Sci Rep 6(32258-32258, 2016. PMID: 27558531. DOI: $10.1038 /$ srep32258

25 Bach D-H, Luu T-T-T, Kim D, An YJ, Park S, Park HJ and Lee SK: Bmp4 upregulation is associated with acquired drug resistance and fatty acid metabolism in egfr-mutant non-smallcell lung cancer cells. Mol Ther Nucleic acids 12: 817-828, 2018. PMID: 30153566. DOI: 10.1016/j.omtn.2018.07.016

26 Kani K, Malihi PD, Jiang Y, Wang H, Wang Y, Ruderman DL, Agus DB, Mallick P and Gross ME: Anterior gradient 2 (agr2): Blood-based biomarker elevated in metastatic prostate cancer associated with the neuroendocrine phenotype. Prostate 73(3): 306-315, 2013. PMID: 22911164. DOI: 10.1002/pros.22569

27 Wayner EA, Quek SI, Ahmad R, Ho ME, Loprieno MA, Zhou Y, Ellis WJ, True LD and Liu AY: Development of an elisa to detect the secreted prostate cancer biomarker agr2 in voided urine. Prostate 72(9): 1023-1034, 2012. PMID: 22072305. DOI: 10.1002/pros.21508

28 Guo H, Zhu Q, Yu X, Merugu SB, Mangukiya HB, Smith N, Li Z, Zhang B, Negi H, Rong R, Cheng K, Wu Z and Li D: Tumorsecreted anterior gradient-2 binds to vegf and fgf 2 and enhances their activities by promoting their homodimerization. Oncogene 36(36): 5098-5109, 2017. PMID: 28481872. DOI: 10.1038/ onc. 2017.132

$29 \mathrm{Cal} \mathrm{S}$ and López-Otín C: Adamts proteases and cancer. Matrix Biol 44-46: 77-85, 2015. PMID: 25636539. DOI: 10.1016/j.matbio.2015.01.013

30 Duc-Hiep B and Sang Kook Lee: The potential impacts of tylophora alkaloids and their derivatives in modulating inflammation, viral infections, and cancer. Curr Med Chem 25: 116, 2018. PMID: 30047325 DOI: 10.2174/092986732566618 0726123339

31 Kim WK, Bach D-H, Ryu HW, Oh J, Park HJ, Hong J-Y, Song $\mathrm{H}-\mathrm{H}$, Eum S, Bach TT and Lee SK: Cytotoxic activities of telectadium dongnaiense and its constituents by inhibition of the wnt/ $\beta$-catenin signaling pathway. Phytomedicine 34: 136-142, 2017. PMID: 28899495. DOI: 10.1016/j.phymed.2017.08.008

32 Um S, Bach D-H, Shin B, Ahn C-H, Kim S-H, Bang H-S, Oh KB, Lee SK, Shin J and Oh D-C: Naphthoquinone-oxindole alkaloids, coprisidins a and $\mathrm{b}$, from a gut-associated bacterium in the dung beetle, copris tripartitus. Org Lett 18(22): 5792-5795, 2016. PMID: 27934498. DOI: 10.1021/acs.orglett.6b02555 
33 Huong PT, Nguyen LT, Nguyen X-B, Lee SK and Bach D-H: The role of platelets in the tumor-microenvironment and the drug resistance of cancer cells. Cancers 11(2): 240, 2019. PMID: 30791448. DOI: $10.3390 /$ cancers 11020240.

34 Bach DH, Park HJ and Lee SK: The dual role of bone morphogenetic proteins in cancer. Mol Ther Oncolytics 8: 1-13, 2018. PMID: 29234727. DOI: 10.1016/j.omto.2017.10.002

35 Bach DH, Hong JY, Park HJ and Lee SK: The role of exosomes and mirnas in drug-resistance of cancer cells. Int J Cancer 141(2): 220-230, 2017. PMID: 28240776. DOI: $10.1002 / \mathrm{ijc} .30669$

36 Bach DH, Lee SK and Sood AK: Circular rnas in cancer. Mol Ther Nucleic Acids 16: 118-129, 2019. PMID: 30861414. DOI: 10.1016/j.omtn.2019.02.005

37 Bach DH and Lee SK: Long noncoding rnas in cancer cells. Cancer Lett 419: 152-166, 2018. PMID: 29414303. DOI: 10.1016/j.canlet.2018.01.053

38 Bach DH, Long NP, Luu TT, Anh NH, Kwon SW and Lee SK: The dominant role of forkhead box proteins in cancer. Int J Mol Sci 19(10), 2018. PMID: 30360388. DOI: 10.3390/ijms 19103279

39 Wei C, Yao X, Jiang Z, Wang Y, Zhang D, Chen X, Fan X, Xie C, Cheng J, Fu J and Leung EL: Cordycepin inhibits drugresistance non-small cell lung cancer progression by activating ampk signaling pathway. Pharmacol Res 144(79-89, 2019. PMID: 30974169. DOI: 10.1016/j.phrs.2019.03.011

40 Jin Q, Zhou J, Xu X, Huang F and Xu W: Hypoxia-inducible factor-1 signaling pathway influences the sensitivity of hcc827 cells to gefitinib. Oncol Lett 17(4): 4034-4043, 2019. PMID: 30881515. DOI: $10.3892 / \mathrm{ol} .2019 .10025$

$41 \mathrm{Liu} \mathrm{Z}$ and Gao W: Overcoming acquired resistance of gefitinib in lung cancer cells without $7790 \mathrm{~m}$ by azd9291 or twist 1 knockdown in vitro and in vivo. Arch Toxicol 93(6): 1555-1571, 2019. PMID: 30993382. DOI: 10.1007/s00204-019-02453-2

42 Sanomachi T, Suzuki S, Togashi K, Seino S, Yoshioka T, Kitanaka C, Okada M and Yamamoto M: Brexpiprazole reduces survivin and reverses egfr tyrosine kinase inhibitor resistance in lung and pancreatic cancer. Anticancer Res 39(9): 4817-4828, 2019. PMID: 31519584. DOI: 10.21873/anticanres.13667

43 Kaburagi T, Kiyoshima M, Nawa T, Ichimura H, Saito T, Hayashihara K, Yamada H, Satoh H, Endo T, Inage Y, Saito K, Inagaki M, Hizawa N, Sato Y, Ishikawa H, Sakai M, Kamiyama K, Kikuchi N, Nakamura H, Furukawa K, Kodama T, Yamashita T, Nomura A and Yoshida S: Acquired egfr $\mathrm{t} 790 \mathrm{~m}$ mutation after relapse following egfr-tki therapy: A population-based multiinstitutional study. Anticancer Res 38(5): 3145-3150, 2018. PMID: 29715155 DOI: 10.21873/anticanres.12577

44 Phung CD, Nguyen HT, Tran TH, Choi HG, Yong CS and Kim JO: Rational combination immunotherapeutic approaches for effective cancer treatment. J Control Release 294: 114-130, 2019. PMID: 30553850. DOI: 10.1016/j.jconrel.2018.12.020
45 Phung CD, Tran TH and Kim JO: Engineered nanoparticles to enhance natural killer cell activity towards onco-immunotherapy: A review. Arch Pharm Res 43(1): 32-45, 2020. PMID: 31993969. DOI: $10.1007 / \mathrm{s} 12272-020-01218-1$

46 Alves MR, e Melo NC, Barros-Filho MC, do Amaral NS, Silva FIdB, Baiocchi Neto G, Soares FA, de Brot Andrade L and Rocha RM: Downregulation of agr2, p21, and cyclin d and alterations in $\mathrm{p} 53$ function were associated with tumor progression and chemotherapy resistance in epithelial ovarian carcinoma. Cancer Med 7(7): 3188-3199, 2018. PMID: 29845750. DOI: $10.1002 / \mathrm{cam} 4.1530$

47 Bach D-H, Zhang W and Sood AK: Chromosomal instability in tumor initiation and development. Cancer Res 79(16): 3995-4002, 2019. PMID: 31350294. DOI: 10.1158/0008-5472.CAN-18-3235

48 Brychtova V, Vojtesek B and Hrstka R: Anterior gradient 2: A novel player in tumor cell biology. Cancer Lett 304(1): 1-7, 2011. PMID: 21371820. DOI: 10.1016/j.canlet.2010.12.023

49 Zhang Y, Xia F, Zhang F, Cui Y, Wang Q, Liu H and Wu Y: Mir$135 \mathrm{~b}-5 \mathrm{p}$ enhances doxorubicin-sensitivity of breast cancer cells through targeting anterior gradient 2. J Exp Clin Cancer Res 38(1): 26, 2019. PMID: 30665445. DOI: 10.1186/s13046-019-1024-3

50 Liu QG, Li YJ and Yao L: Knockdown of agr2 induces cell apoptosis and reduces chemotherapy resistance of pancreatic cancer cells with the involvement of erk/akt axis. Pancreatology 18(6): 678-688, 2018. PMID: 30055941. DOI: 10.1016/j.pan.2018.07.003

51 Rayan A, Raiyn J and Falah M: Nature is the best source of anticancer drugs: Indexing natural products for their anticancer bioactivity. PloS One 12(11): e0187925-e0187925, 2017. PMID: 29121120. DOI: 10.1371/journal.pone.0187925

52 Bae SY, Hong J-Y, Lee H-J, Park HJ and Lee SK: Targeting the degradation of axl receptor tyrosine kinase to overcome resistance in gefitinib-resistant non-small cell lung cancer. Oncotarget 6(12): 10146-10160, 2015. PMID: 25760142. DOI: 10.18632/oncotarget.3380

$53 \mathrm{Hu} \mathrm{Y,} \mathrm{Qiu} \mathrm{Y,} \mathrm{Yagüe} \mathrm{E,} \mathrm{Ji} \mathrm{W,} \mathrm{Liu} \mathrm{J} \mathrm{and} \mathrm{Zhang} \mathrm{J:} \mathrm{Mirna-205}$ targets vegfa and fgf2 and regulates resistance to chemotherapeutics in breast cancer. Cell Death Dis 7(6): e2291e2291, 2016. PMID: 27362808. DOI: 10.1038/cddis.2016.194

54 Keklikoglou I, Kadioglu E, Bissinger S, Langlois B, Bellotti A, Orend G, Ries $\mathrm{CH}$ and De Palma M: Periostin limits tumor response to vegfa inhibition. Cell Rep 22(10): 2530-2540, 2018. PMID: 29514082. DOI: 10.1016/j.celrep.2018.02.035

Received February 9, 2020

Revised February 18, 2020

Accepted February 19, 2020 